Austral Cmunicación

\title{
Matriz para el estudio de noticias televisivas sobre delito, violencia e inseguridad: una articulación teórico-metodológica
}

\author{
Natalia Aruguete \\ nataliaaruguete@gmail.com \\ CONICET - Universidad Nacional de Quilmes, Programa ICEP \\ Natalia Raimondo Anselmino \\ natalia_raimondo@hotmail.com \\ CONICET - Universidad Nacional de Rosario - \\ Universidad Abierta Interamericana, Rosario
}

Esteban Andrés Zunino

estebanzunino@gmail.com

CONICET - Universidad Nacional de Cuyo - Universidad Juan Agustín Maza - Universidad Nacional de Quilmes, Programa ICEP

\section{Nadia Sabrina Koziner}

nadiakoziner@gmail.com

CONICET - Universidad de Buenos Aires, IEALC -

Universidad Nacional de Quilmes, Programa ICEP

Gabriela Fabbro

fabbrogabriela@gmail.com

Facultad de Comunicación, Universidad Austral, Buenos Aires

Recibido: 11 de mayo de 2018 Aceptado: 30 de octubre de 2018 


\begin{abstract}
Resumen
En este artículo se presenta una matriz especialmente diseñada para el análisis de noticias televisivas sobre delito, violencia e inseguridad. Se trata de un instrumento que, si bien fue proyectado tomando como base conceptual, principalmente, las perspectivas del framing y del standing, se ha visto enriquecido a partir de la incorporación de categorías aportadas por la sociosemiótica y el análisis narrativo audiovisual. De este modo, es posible afirmar que esta herramienta es doblemente innovadora: por un lado, la misma ha sido especialmente proyectada para ser aplicada a un tipo de textualidad mediática en particular (las noticias televisivas sobre delito, violencia e inseguridad) y; por otro lado, es producto de un proceso de triangulación teórico-metodológico cuyo propósito motor ha sido sortear la tendencia (presente en ciertos análisis de contenido) a producir inferencias que devienen más de un juicio a priori por parte del investigador que de aquello que emana tanto del propio texto como de su puesta en discurso. Se espera que esta pueda ser reutilizada en futuras investigaciones afines.
\end{abstract}

Palabras clave: delito, inseguridad, noticias televisivas, framing, análisis narrativo audiovisual, sociosemiótica.

\title{
A matrix for the study of television news on crime, violence, and insecurity: a theoretical and methodological articulation
}

\begin{abstract}
In this article, we present a matrix that is especially designed for the analysis of television news about crime, violence, and insecurity. Although this tool was conceived with framing and standing perspectives as our conceptual bedrock, it was enriched with categories from sociosemiotics and audiovisual narrative analysis. For this reason, we can affirm that this tool is doubly innovative: on the one hand, it is specifically meant for a particular kind of media text (television news about crime, violence, and insecurity); and, on the other hand, it is the result of a process of theoretical and methodological triangulation, the purpose of which is to avoid the tendency, in certain content analyses, to infer conclusions based more on the investigator's biases than on what emerges from the actual text and how it organizes its discourse. We hope this matrix can be reused in future related investigations.
\end{abstract}

Keywords: crime, insecurity, television news, framing, audiovisual narrative analysis, sociosemotics.

\section{Matriz para estudo das notícias televisivas sobre crime, violência e insegurança: uma articulação teórico-metodológica}

\section{Resumo}

Este artigo apresenta uma matriz especialmente projetada para a análise de notícias televisivas sobre crime, violência e insegurança. Trata-se de um instrumento que, apesar de ter sido projetado tomando-se como base conceitual principalmente as perspectivas do framing e standing, tem sido enriquecido pela incorporação de categorias contribuídas pela sociossemiótica e pela análise narrativa audiovisual. Assim, pode-se dizer que essa ferramenta é duplamente inovadora: por um lado, tem sido especialmente projetada para ser aplicada a um tipo de textualidade midiática em particular (as notícias de TV sobre crime, violência e insegurança) e, por outro lado, é produto de um processo de triangulação teórico-metodológico, cujo objetivo tem sido superar a tendência (presente em certas análises de conteúdo) a produzir inferências que advém mais de um juízo a priori pelo investigador, do que aquele que emana tanto do próprio texto 
quanto de sua colocação no discurso. Espera-se que esta possa ser reutilizada em futuras pesquisas afins.

Palavras chave: crime, insegurança, notícias televisivas, framing, análise narrativa audiovisual, sociossemiótica.

\section{Introducción}

En este artículo realizamos la presentación teórico-epistemológica del instrumento de análisis elaborado en el marco de una investigación sobre el circuito productivo de las noticias de delito, violencia e inseguridad ${ }^{1}$. Parte de ese estudio analiza el contenido noticioso y su construcción discursiva articulando dos planos de la textualidad audiovisual: el plano del contenido y el plano del discurso.

Las investigaciones sobre textualidades mediáticas suelen enfocarse en uno de los dos niveles mencionados de manera excluyente, ofreciendo un abordaje más sesgado que el que nos proponemos. El análisis de tipo cuantitativo sobre el plano del contenido nos brinda una mirada macro del paquete textual trabajado y nos permite establecer regularidades empíricas en el comportamiento de algunas de las dimensiones de los textos, mientras que el estudio del plano de la puesta en discurso habilita que se reconozcan operaciones subyacentes en la dimensión enunciativa que, de otro modo, no podrían ser aprehendidas.

La relevancia de centrarnos en las noticias sobre delito, violencia e inseguridad reside en que estas ocupan un lugar central en las agendas política, mediática y pública de América Latina (Lagos \& Dammert, 2012). Ello se explica, en parte, porque el continente cobija a dieciocho de los veinte países más violentos del planeta (Sozzo, 2016). En la Argentina, las encuestas de victimización señalan que en el 27,5\% de los hogares al menos uno de sus miembros ha sido víctima de delito. La percepción subjetiva de inseguridad ${ }^{2}$, por su parte, ha permanecido en valores mucho más altos que los de victimización, superando el 80\% en todos los años del período 2010-2015 (Muratori \& Espíndola, 2016). La inseguridad, así concebida, es percibida como una sensación de indefensión de los individuos contra una amenaza aleatoria, que opera con autonomía relativa respecto de los hechos delictivos: "la discusión sobre si la inseguridad es una sensación o es real [...] no tiene resolución posible: [...] ambas definiciones están pre-

Este artículo se inscribe en el Proyecto de Investigación Orientada (PIO 2015-2016 CONICET - Defensoría del Público) y en el Proyecto de Investigación Científica y Tecnológica (MINCyT) 2015 "De la propiedad a la recepción. Estudio integral del circuito productivo de las noticias sobre delito e inseguridad en los noticieros televisivos de mayor audiencia de la Argentina". Está dirigido por Gabriel Kessler y Natalia Aruguete en el PIO, y por Martín Becerra en el PICT, y es llevado a cabo por un grupo de investigadores argentinos provenientes de distintas provincias del país.

2 Kessler (2009) sostiene que el término inseguridad es una prenoción sociológica, una forma de explicar la realidad del sentido común antes que un concepto desarrollado por las ciencias sociales (p. 11), que incluye tanto delitos como situaciones que, sin llegar a serlo, producen sensación de temor. 
Natalia Aruguete, Natalia Raimondo Anselmino, Esteban Andrés Zunino, Nadia Sabrina Koziner, Gabriela Fabbro

Matriz para el estudio de noticias televisivas sobre delito, violencia e inseguridad: una articulación teórico-metodológica

sentes en forma indisociable" (Kessler, 2009, p. 12). Las dimensiones objetiva y subjetiva de la inseguridad se interrelacionan y se retroalimentan y, en ese proceso, los medios de comunicación son considerados actores centrales.

Estudios previos (Calzado, 2012, 2015; Llorenç Valcarce, 2009; Martini, 2012; Rodríguez Alzueta, 2014) sostienen que, desde la década de 1990, los medios han contribuido con la cristalización de un nuevo estereotipo de delincuente. Al trazar una línea divisoria entre un "nosotros" merecedor de la seguridad, encarnado en el "buen ciudadano" o el "vecino", y un "otro", asociado al joven pobre de barrios marginales, se señala en dónde se focaliza el peligro y contra qué y quiénes el Estado debe actuar en la formulación de políticas públicas. Asimismo, la construcción simbólica de la inseguridad implica una espacialidad y una temporalidad que le son propias (Kessler, 2013). Los barrios marginales y sus habitantes son estigmatizados, y se delinea una separación entre territorios seguros e inseguros. El relato del delito suele construirse en referencia a un pasado mítico de seguridad y libertad que se contrapone a un presente de riesgos y de miedos.

La tesis de que los medios de comunicación son los responsables del sentimiento de inseguridad es puesta en cuestión a partir del análisis de otras variables ligadas al entorno, la cultura y la experiencia. No obstante, existe consenso acerca de que estos desempeñan un rol significativo en la creación de un estado de riesgo que trae aparejadas demandas de mayor control social y punitividad (Entel, 2007; Killias, 1991; Martini, 2012).

A continuación, se glosan las perspectivas teóricas articuladas, se identifican las unidades de análisis, se desarrollan las dimensiones y variables de la matriz en cuestión y se concluye con algunas reflexiones en torno al proceso de diseño instrumental.

\section{Perspectivas teóricas involucradas}

El instrumento que aquí desarrollamos procura reconocer dos tipos de determinaciones de las textualidades bajo estudio, las del contenido y las del discurso. Para su elaboración, por tanto, hemos recuperado conceptos y categorías propias de la teoría del Framing, el Standing, la sociosemiótica y la narrativa audiovisual.

La teoría del Framing estudia el proceso de transmisión de significados, signos, símbolos y valores de la sociedad a los medios y viceversa (Amadeo, 2008). Teniendo en cuenta que los frames son principios de la organización de la información que se encuentran en el emisor, en los individuos receptores del discurso mediático y en las prácticas sociales y culturales (Cohen y Wolfsfeld, 1993), en esta investigación nos enfocamos en los encuadres noticiosos (news frames) presentes en las noticias sobre delito, violencia e inseguridad de los noticieros televisivos bajo estudio. 
Entre las definiciones de frames que hacen foco en el proceso de elaboración de las noticias se encuentra la de Entman (2003), para quien encuadrar

[...] implica seleccionar y realzar algunos aspectos de eventos o temas, y hacer conexiones entre ellos para promover una interpretación, evaluación y/o solución. Las palabras e imágenes que componen un encuadre pueden ser distinguidas de las demás noticias por su capacidad para estimular apoyo u oposición a los distintos campos de un conflicto político (Entman, 2003, p. 417).

Los frames promovidos por las fuentes oficiales y por actores económica y culturalmente poderosos suelen tener mayor presencia en los contenidos mediáticos (Gans, 2004). Por ello y a los efectos de analizar el rol de las fuentes en las noticias sobre delito, violencia e inseguridad, se propone el concepto de standing desarrollado por Ferree, Gamson, Gerhards y Rucht (2002). Esta noción alude a la capacidad de un actor -individual o colectivo- de tener voz en los medios de comunicación. En este sentido, asumimos que la mera presencia mediática de las fuentes no garantiza que puedan expresar su percepción acerca de la situación relatada ni que esta sea acreditada por el medio. Es así como para conocer el tipo de tratamiento que reciben las fuentes en la cobertura noticiosa deben considerarse tanto su visibilidad como la acreditación o desacreditación que el medio realiza de su testimonio. Esta premisa se deriva del planteo de Charron (1998) acerca de que "la influencia en la agenda de los asuntos públicos se mide por la capacidad que tiene un actor de imponer o condicionar [...] cierta definición de la realidad" (p. 76).

La perspectiva sociosemiótica, además, se orienta a la comprensión de los procesos de producción de sentido, planteando un análisis que indaga en las modalidades de enunciación y en las estrategias discursivas -desde un punto de vista no-intencional (Raimondo Anselmino, 2011) - de producción de significados. De este modo, el estudio del nivel del enunciado llevado a cabo a partir del análisis de contenido es enriquecido con la incorporación de categorías provenientes de aquel centrado en el nivel de la enunciación, plano del discurso "en el que se construye, no lo que se dice, sino la relación del que habla a aquello que dice” (Sigal \& Verón, 2008, p. 23) y, derivadamente, la relación que quien habla propone al destinatario ${ }^{3}$. Se trata de una teoría que concibe el discurso como sistema organizado de significaciones articuladas y articuladoras del sentido social (Verón, 1998), y que reconoce aquellas operaciones que son huella de las condiciones sociales bajo las cuales estos discursos han sido producidos.

Como es posible advertir, nuestro proyecto aborda un tipo de discurso en particular -que Verón (2004) denomina discurso de la información cuyo objeto es la actualidad- en soporte audiovisual televisado. Comprende producciones diarias, únicas y de

\footnotetext{
Se mencionan así los tres aspectos que, según Sigal y Verón (2008), dan lugar a un dispositivo enunciativo que supone la construcción discursiva del enunciador, del destinatario y de la relación entre ambos.
} 
Natalia Aruguete, Natalia Raimondo Anselmino, Esteban Andrés Zunino, Nadia Sabrina Koziner, Gabriela Fabbro

Matriz para el estudio de noticias televisivas sobre delito, violencia e inseguridad: una articulación teórico-metodológica

emisión regular, y supone una cierta serialización y rutinización en el proceso de su producción (Barroso, 2002). La dimensión narrativa ocupa aquí un lugar nodal y, por ello, es necesario hacer uso, también, de algunas categorías propias del análisis narrativo audiovisual en pos de recuperar

la facultad o capacidad de que disponen las imágenes visuales y acústicas para contar historias, es decir, para articularse con otras imágenes y elementos portadores de significación hasta el punto de configurar discursos constructivos de textos, cuyo significado son las historias (García Jiménez, 1993, pp.13-14).

Según Farré (2004), el género informativo audiovisual procura satisfacer las expectativas del público en virtud de un pacto de credibilidad y confianza, cuyo principal aspecto es la provisión de contenidos, un mundo posible.

Las distintas teorías presentadas aquí se han conjugado para la elaboración de una matriz que, si bien fue estructurada tomando como base conceptual, fundamentalmente, las perspectivas del framing y del standing, ha sido enriquecida a partir de la incorporación de categorías aportadas por la sociosemiótica y el análisis narrativo audiovisual, lo que da lugar a un instrumento de análisis innovador. Como veremos luego, dicha articulación procura evitar la tendencia, presente en ciertos análisis de contenido, a producir inferencias que devienen más de un juicio a priori por parte del investigador que de aquello que emana del propio texto y su puesta en discurso ${ }^{4}$.

\section{Unidades de análisis}

La matriz presentada en este artículo fue elaborada para el estudio de un conjunto de noticias del ámbito nacional sobre delito, violencia e inseguridad puestas al aire en los noticieros transmitidos, durante el horario central (prime time), por los canales 11 y 13 del Área Metropolitana de Buenos Aires (AMBA); 10 y 12 de Córdoba; 3 y 5 de Rosario, y 9 y 7 de Mendoza, en la semana que va del 1 al 5 de agosto de 2016 (tabla 1). Los canales mencionados pertenecen a los cuatro conglomerados urbanos más poblados de la Argentina ${ }^{5}$ y fueron seleccionados por el volumen de su audiencia, con excepción del Canal 10, cuya elección se debió a criterios de diferenciación (su condición de ser público y depender de una universidad nacional).

\footnotetext{
4 A una similar apreciación arriban Matthes y Kohring (2008) al describir los distintos tipos de análisis de contenido y analizar los problemas de fiabilidad y validez. En función de ello argumentan, luego, que el análisis de clusters es más confiable o válido en tanto los codificadores no saben de antemano qué frame están rastreando.

5 Según el último Censo Nacional de Población, Hogares y Viviendas (INDEC, 2010), el AMBA tiene 12.800.000 habitantes; Córdoba, 1.391.000; Rosario, 1.198.000, y Mendoza, 937.000.
} 
Austral Comunicación

Volumen 7 número 2 (diciembre de 2018): 229-250. ISSN 2313-9129

Tabla 1. Unidades de análisis (elaboración propia)

\begin{tabular}{llc}
\hline Ciudad & Canal & Cantidad de noticias \\
\hline CABA & Canal 11 & 26 \\
\hline & Canal 13 & 38 \\
\hline Córdoba & Canal 10 & 13 \\
\hline & Canal 12 & 6 \\
\hline Rosario & Canal 3 & 24 \\
\hline & Canal 5 & 21 \\
\hline Mendoza & Canal 9 & 29 \\
\hline & Canal 7 & 35 \\
\hline
\end{tabular}

Entre todas las noticias, enfocamos nuestro análisis en tres tipos de géneros periodísticos en particular -informes, crónicas y móviles- que conforman las unidades de muestreo, es decir, unidades físicas, semántica y lógicamente independientes unas de otras, que deben ser recogidas y conservadas para su estudio (Colle, 2011). Dentro de cada una de estas es posible identificar unidades de registro, segmentos específicos del contenido que se relacionan lógica y semánticamente con otras unidades de registro de una misma unidad de muestreo.

El informe periodístico, también considerado usualmente como reportaje, es un género periodístico que consiste en la profundización de una noticia -situándose en los límites del periodismo interpretativo- y supone análisis y valoración de los hechos narrados. Suele reponer los antecedentes de una noticia, no descubrirla, sino profundizar en ella, por considerarla de interés público y de actualidad (Hills, 1987). En este caso, el testimonio y la valoración de los sujetos implicados (víctimas, victimarios, testigos, expertos, etc.) son los principales protagonistas. El informe puede ser el resultado de una investigación previa o adoptar una estructura de problema-solución sobre la base de una serie de preguntas. Esta unidad de muestreo puede incluir otras unidades de registro.

La crónica, por su parte, narra acontecimientos de actualidad según su organización cronológica y suele no admitir procedimientos de ficcionalización o de dramatización. Su objetivo es brindar información desprovista de recursos expresivos propios de la ficción, tales como efectos especiales o musicalización de fondo, entre otros.

Por último, el móvil consiste en una transmisión desde exteriores (en espacio exterior o interior), es decir, fuera del estudio desde el cual se transmite el noticiero. Implica el traslado de equipo técnico y periodista a cargo (movilero, reportero o cronista) y ofrece un relato en simultáneo a un hecho noticioso. En este género intervie- 
Natalia Aruguete, Natalia Raimondo Anselmino, Esteban Andrés Zunino, Nadia Sabrina Koziner, Gabriela Fabbro

Matriz para el estudio de noticias televisivas sobre delito, violencia e inseguridad: una articulación teórico-metodológica

nen los factores de la espacialidad física y la temporalidad: el periodista está en el aquí y ahora, mientras transcurre el acontecimiento.

En total, la matriz se aplicó a un conjunto de 192 noticias, distribuidas de la siguiente manera: 26 de canal 11;38, del 13; 13, del 10; 6, del 12; 34, del 3; 21, del 5; 29, del 9, y 35, del 7 (tabla 1).

\section{Desarrollo de la matriz}

La matriz elaborada para el análisis de las noticias sobre delito, violencia e inseguridad está compuesta por 73 variables y sus respectivas categorías ${ }^{6}$, organizadas en seis dimensiones (figura 1) que pueden sintetizarse del siguiente modo: aquellas referidas al acontecimiento noticiado y su relevancia dentro del noticiero; a los protagonistas involucrados en él; a la geolocalización del acontecimiento; a los encuadres que definen la situación problemática; al tratamiento de las fuentes de información; al modo como se narra, tanto desde el punto de vista cognitivo como audiovisual, y a los recursos narrativos que se emplean para su puesta en escena.

Para crear las variables se combinaron distintas perspectivas teóricas cuya articulación permite desentrañar las singularidades del tipo de contenido informativo estudiado. Ello puede observarse, por ejemplo, en variables como Calificación de la víctima, en la que se recogen apelativos que serán considerados, luego y por fuera de esta matriz, para un análisis del discurso centrado en las figuraciones. Otro ejemplo es el de Focalización, variable propia de la narratología modal que atiende a recuperar el punto de vista cognitivo presentado en el relato (Genette, 1989) ${ }^{7}$. Producto de este diálogo conceptual, encontramos rasgos que permiten aprehender la multidimensionalidad del objeto, un logro imposible de habernos encapsulado de manera aislada en perspectivas teóricas.

En este punto, cabe destacar el esfuerzo emprendido de triangulación teórico-metodológica. El eje que define las estrategias de investigación trianguladas es que orientan su atención a unidades comunes de observación. El concepto de triangulación, recordemos, deriva de la geometría aplicada a la navegación y es utilizado metafóricamente para definir un objeto de estudio a partir del entrecruzamiento de líneas trazadas desde distintos puntos de vista. El contraste de tales perspectivas ofrece una imagen más completa de un objeto, para lo cual es necesario definir la ubicación desde

\footnotetext{
Se entiende por variable una propiedad que puede cambiar su valor, y por categoría, el valor que puede asumir dicha variación.

Si bien las categorías provenientes de la narratología modal -entre ellas, las de focalización, ocularización y auricularización- fueron elaboradas en función del análisis de textos ficcionales, su empleo no se restringe necesariamente a ese tipo de discursos. Gaudreault y Jost (1995), por ejemplo, han advertido eso al reflexionar sobre las conexiones y tensiones entre la actitud documentalizante y la actitud ficcionalizante de todo filme y algo similar puede leerse en Orza (2002).
} 
Austral Comunicación

Volumen 7 número 2 (diciembre de 2018): 229-250. ISSN 2313-9129

la cual se orienta cada teoría y reducir su sesgo (Gallart, 2002). Se trata de una aproximación que aporta conocimiento interpretativo y permite elaborar hipótesis complementarias de aquellas que enuncian regularidades.

Entendemos que la investigación es un proceso cognitivo antes que uno de validación de ideas previamente formuladas. Consideramos que ello es así aun cuando el instrumento matriz es propio de una investigación que recurre a técnicas cuantitativas - para alcanzar una sistematización de los rasgos de las noticias con el objeto de establecer similitudes y diferencias entre estos- en tanto articulamos distintos enfoques teórico-metodológicos.

En este contexto, una consecuencia de la convergencia teórico-metodológica es diferenciar entre dos tipos de variables: inferenciales y de reconocimiento. Las primeras (en adelante, identificadas como VI) aluden a aspectos que no están manifiestamente mencionados en el contenido y, por esa razón, el observador debe deducirlas; las segundas (VR), en cambio, aparecen materializadas en el texto.

A continuación, desarrollamos y definimos operacionalmente las distintas variables que componen cada una de las seis dimensiones presentadas en Figura 1.

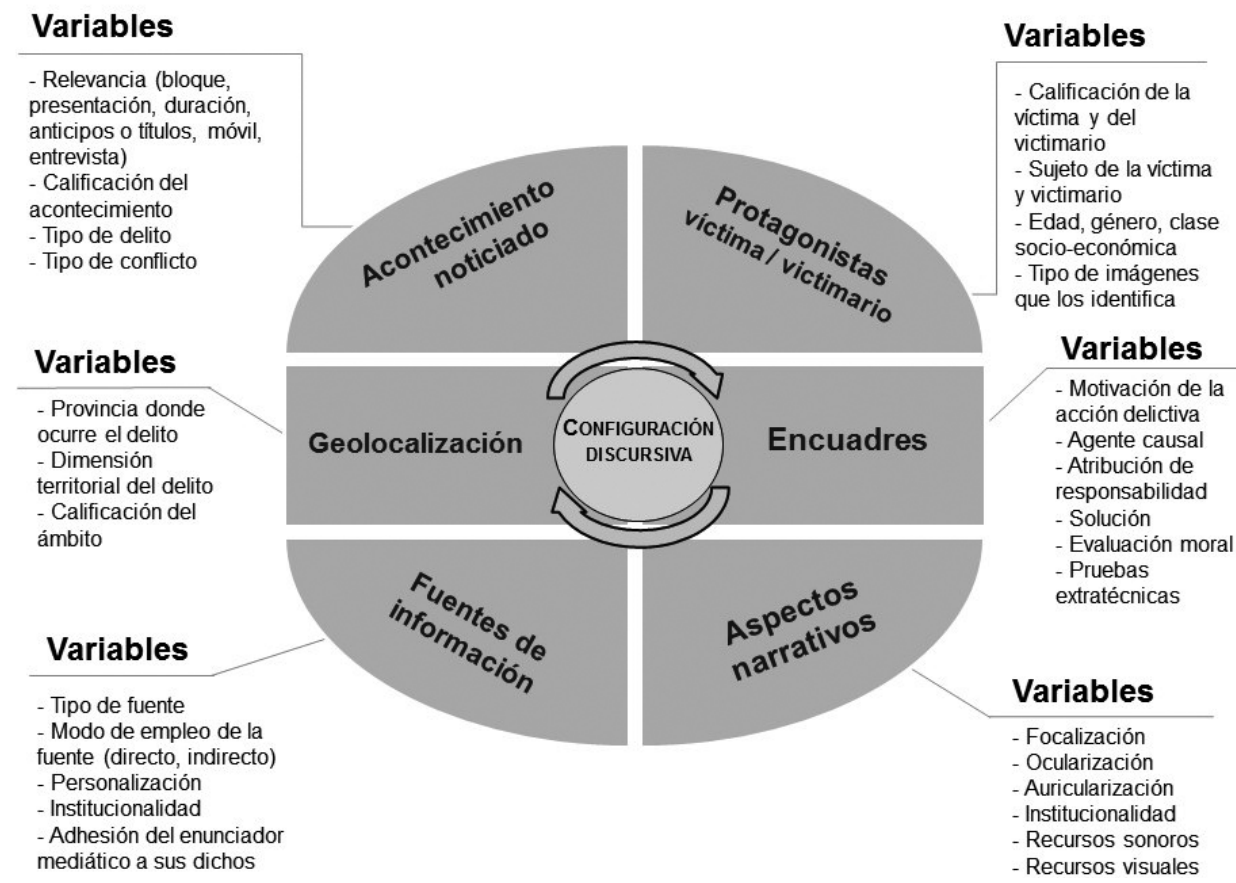

Figura 1. Dimensiones y variables de la matriz (elaboración propia). 
Natalia Aruguete, Natalia Raimondo Anselmino, Esteban Andrés Zunino, Nadia Sabrina Koziner, Gabriela Fabbro

Matriz para el estudio de noticias televisivas sobre delito, violencia e inseguridad: una articulación teórico-metodológica

En relación con la primera dimensión, nos centramos en la definición del acontecimiento y su relevancia. Siguiendo a Verón (1987a), entendemos que aquello que habitualmente definimos como actualidad es resultado de un determinado proceso de fabricación que tiene la noticia como producto. En este sentido, asumimos que los medios producen realidad social cuando nos "relatan cotidianamente lo que ocurre en el mundo" (p. ii). Como afirma este autor:

\begin{abstract}
los hechos que componen esta realidad social no existen en tanto tales (en tanto hechos sociales) antes de que los medios los construyan. Después que los medios los han producido, en cambio, estos hechos tienen todo tipo de efectos [...] [y] los acontecimientos sociales empiezan a tener múltiples existencias, fuera de los medios (Verón, 1987a, pp. IV-V).
\end{abstract}

Una parte importante de esa construcción está dada, por ejemplo, por los términos con los cuales se designa eso que acontece o los modos como se presenta la información.

Asimismo, la relevancia comprende el conjunto de rasgos formales que afectan el nivel de visibilidad de la información. La atribución mediática de relevancia a determinados acontecimientos puede derivar en lo que Fernández Pedemonte (2010) denomina olas de violencia. La mediatización de casos conmocionantes modifica los criterios de selección de las redacciones, lo que favorece la construcción de series en las que el tratamiento binario entre lo legal y lo ilegal se reproduce y normaliza, lo cual genera una conexión y la consecuente amplificación de cierto tipo de hechos no necesariamente ligados entre sí. En relación con el acontecimiento y su relevancia, hemos discriminado las siguientes variables:

- Calificación del acontecimiento (VR), en la que se listan todos los términos, ya sean sustantivos o adjetivos, utilizados para denominarlo en el plano lingüístico verbal, tanto en la oralidad de los presentadores u otros actores como en el texto sobreimpreso.

- Tipo de delito (VI), que sistematiza una tipología para integrar diversos acontecimientos a partir de su similaridad semántica. Incluye las siguientes categorías: 1. Robo y hurto / 2. Secuestro / 3. Asesinato / 4. Narcotráfico / 5. Amenaza / 6. Violencia sexual / 7. Femicidio / 8. Violencia de género / 9. Violencia intrafamiliar / 10. Violencia infantil / 11. Violencia Institucional / 12. Violencia en cárceles / 13. Violencia en las calles o en la comunidad / 14. Violencia laboral / 15. Corrupción en el ámbito público / 16. Corrupción en el ámbito privado / 17. Delitos medioambientales / 18. Seguridad vial / 19. Salubridad / 20. Inseguridad Informática / 21. Otros.

- Bloque en el que aparece (VR), que identifica el fragmento del noticiero comprendido entre tandas publicitarias (Orza, 2002), a saber: 1. Primer bloque / 2. 
Austral Comunicación

Volumen 7 número 2 (diciembre de 2018): 229-250. ISSN 2313-9129

Segundo bloque / 3. Tercer bloque / 4. Cuarto bloque / 5. Quinto bloque / 6. Sexto bloque. / 7. Más de un bloque / 8. Otros.

- Duración de la noticia (VR), que consigna el tiempo que dura la nota -unidad de muestreo- en minutos y segundos.

- Aparición en los anticipos y/o títulos (VR), en la que se computa si la noticia aparece referenciada previamente. Los títulos y los anticipos cumplen una función identificadora (Genette \& Crampé, 1988) de las noticias a partir de una serie de signos lingüísticos o recursos audiovisuales que aparecen al comienzo del noticiero (o de cada bloque) para designarlas, indicar su contenido general o llamar la atención del público.

- Presentación de la noticia (VR), que reconoce la presencia o no de una introducción a la noticia por parte de los conductores.

- Inclusión o no de narraciones complementarias (VR), que contempla, solamente, la presencia de móvil o de entrevista en piso.

- Tipo de conflicto que desencadena (VI), entendiendo por conflicto la "diferencia de intereses percibida, $o$ una creencia que las partes, en sus aspiraciones normales, no pueden alcanzar simultáneamente" (Redorta, 2004: s/p). Se describen: 1. Interno o intrapersonal: del sujeto consigo mismo / 2. Interpersonal: entre dos personas / 3. Intragrupal: entre dos grupos sociales pequeños / 4. Intergrupal: pelea entre dos grupos sociales más amplios / 5. Con el entorno: acción de un actor (individual o colectivo) sobre el entorno físico-ambiental que pueda derivar en una situación de delito o violencia / 6. Otros.

En cuanto a la segunda dimensión, los protagonistas del acontecimiento, los individuos involucrados en el hecho narrado constituyen un aspecto fundamental de la construcción social del delito. Ciertos modos de identificarlos fomentan procesos simbólicos de construcción de enemigos internos y externos que aglutinan dos campos contrapuestos: el de los ciudadanos merecedores de protección -las víctimas- y el de aquellos que por sus conductas se convierten en enemigos "de todos" -los victimarios(Bailone, 2016; Zaffaroni, 2012, 2016). Esta dimensión recoge información sobre la víctima y el victimario principales y secundarios, y reconoce:

- Edad (VI), categorizada mediante franjas etarias: 0 . No es posible identificar / 1 . Entre 0 y 6 años / 2. Entre 7 y 12 años / 3. Entre 13 y 18 años / 4. Entre 19 y 25 años / 5. Entre 26 y 40 años / 6 . Entre 41 y 60 años / 7. Entre 61 y 70 años / 8. Más de 70 años / 99. No es posible codificar. 
Natalia Aruguete, Natalia Raimondo Anselmino, Esteban Andrés Zunino, Nadia Sabrina Koziner, Gabriela Fabbro

Matriz para el estudio de noticias televisivas sobre delito, violencia e inseguridad: una articulación teórico-metodológica

- Género (VI), que distingue entre: 0. No es posible identificar / 1. Masculino / 2. Femenino / 3. Otros (de codificarse esta opción se transcribe el modo como el medio define la mención) / 99. No es posible codificar.

- Clase socioeconómica (VI), que se desglosa en: 0. No es posible identificar / 1. Indigencia / 2. Clase baja / 3. Clase media / 4. Clase alta / 5. Otros. / 99. No es posible codificar. Esta variable permite identificar casos en los cuales la construcción simbólica de la figura del victimario recae en personas provenientes de los sectores populares, frente a los sectores medios y altos urbanos, que suelen ser habitualmente configurados como víctimas (Kessler, 2013; Rodríguez Alzueta, 2014).

- Calificaciones (VR), mediante las cuales se los nombra; en otras palabras, todos aquellos apelativos ${ }^{8}$ utilizados en el plano lingüístico verbal para denominar a quien es identificado como víctima o como victimario, tanto en la oralidad de los presentadores u otros actores, como en el texto sobreimpreso.

- Tipo de sujeto que desencadena la acción (VR), que distingue si el protagonista (víctima o victimario) es presentado individualmente, como grupo o como colectivo, discriminando entre: 0 . No es posible identificar / 1. Individual / 2. Grupo (conjunto de personas no institucionalizadas) / 3. Colectivo (un conjunto de personas que están institucionalizadas) / 99. No es posible codificar.

- Tipo de imágenes (VR) con las cuales se los identifica: 1. Imagen fija/estática / 2. Imagen dinámica / 3. Otros. / 4. Más de un tipo de imagen / 99. No corresponde (no hay imágenes).

La tercera dimensión, geolocalización del acontecimiento, resulta trascendente para este trabajo ya que se considera que la construcción mediática de la inseguridad delimita territorios geográficos seguros e inseguros (Calzado, 2015; Rodríguez Alzueta, 2014). La focalización de la cobertura en barrios o localidades asociados a cierto tipo de ilícitos puede repercutir en determinadas conductas de uso del espacio público como, por ejemplo, evitar circuitos delimitados mediáticamente como "inseguros". A su vez, se pretende reconocer si los medios de las diferentes provincias privilegian en sus coberturas acontecimientos circunscriptos a sus áreas de pertenencia, o si incluyen en sus agendas casos de impacto nacional ubicados en territorios alejados. Las variables incluidas en esta dimensión son las siguientes:

\footnotetext{
Siguiendo a Adelstein (1996), entendemos por apelativo a todo término del léxico (ya sean estos pronombres personales, nombres propios, cargos o títulos institucionales o sustantivos orientados a manifestar un determinado tipo de relación o parentesco, entre otros) que "es empleado en el discurso para mencionar a una persona" (p. 29). Estos pueden desempeñar el rol de deícticos y tener, también, carácter predicativo -en tanto por medio de ellos es posible "efectuar una cierta predicación explícita" (p. 29)- y evidencian relaciones sociales.
} 
Austral Comunicación

Volumen 7 número 2 (diciembre de 2018): 229-250. ISSN 2313-9129

- Provincia (VI) en la que transcurre el hecho, que identifica el Estado regional en el cual se desarrolla el acontecimiento.

- Dimensión territorial (VI) del delito narrado, útil para reconocer qué lugares son mencionados predominantemente como relacionados con el delito, la violencia y la inseguridad: 0 . No es posible identificar / 1. Zona rural / 2. Zona urbana (capital de provincia / centro-conurbano) / 3. Asentamiento dentro de una ciudad / 6. Otros. / 99. No es posible codificar.

- Calificación del ámbito donde ocurre el acontecimiento (VR), que lista todos los términos lingüísticos que refieren a dicho lugar, tanto en la oralidad de los presentadores $\mathrm{u}$ otros actores como en el texto sobreimpreso.

La cuarta dimensión, encuadres noticiosos, se basa en la definición operacional de Entman (1993), cuando afirma que encuadrar es definir problemas, diagnosticar sus causas o las fuerzas que lo crean, hacer juicios morales al evaluar el agente que lo causa, medir con qué costos y beneficios y sugerir soluciones, ofreciendo y justificando un tratamiento, o prediciendo sus resultados. La definición del problema, como primer elemento de esta dimensión, se asocia al tipo de delito y a las calificaciones del acontecimiento desarrollados anteriormente. Los otros elementos que componen los encuadres atienden a las variables:

- Tipo de motivación de la acción delictiva (VR), por medio de la cual se reconoce si se manifiesta una motivación 1. racional, entendida como una operación intelectual de cálculo de probabilidades / 2. pasional, cuando se alude a una reacción afectiva.

- Agente causal del problema (VI), en la que se detectan otros promotores del delito que exceden a los victimarios identificados como tales, distinguiendo entre: 0 . No se hace referencia al agente causal / 1. Individual, cuando la responsabilidad del acontecimiento relatado se condensa en una referencia subjetiva en desmedro de una contextualización que identifique otros factores causales / 2. Social, cuando se contextualiza el acontecimiento relatado poniéndolo en relación con las condiciones socio-estructurales en que tuvo lugar / 3. Institucional, cuando el foco causal recae en la acción o inacción de agentes institucionales que desemboca en la comisión del delito u otros acontecimientos colaterales / 4. Legal, si se alude a normas u otros elementos jurídico-legales que expliquen la acción delictiva / 5. Política, cuando la causa del acontecimiento principal se basa o tiene origen en razones político-partidarias / 6. Otra / 99. No es posible codificar. 
Natalia Aruguete, Natalia Raimondo Anselmino, Esteban Andrés Zunino, Nadia Sabrina Koziner, Gabriela Fabbro

Matriz para el estudio de noticias televisivas sobre delito, violencia e inseguridad: una articulación teórico-metodológica

- Pruebas extratécnicas empleadas (VR), en el sentido retórico del término9, de las que se desprenden, a su vez, los siguientes indicadores: si cumplen una función a) Argumentativa, en tanto se utiliza a favor de la tesis que se desea hacer admitir / b) Contra-argumentativa, por cuestionar un argumento ajeno:

1. testimonios o declaraciones,

2. estadística,

3. jurisprudencia,

4. documentos legales, comerciales y de otro tipo,

5. legislación.

- Atribución de responsabilidad (VI), variable latente ${ }^{10}$ que se infiere a partir de reconocer si se atribuye explícitamente responsabilidad sobre el acontecimiento a:

- alguna institución estatal y, en caso afirmativo, a cuál,

- alguna institución no estatal (privada o del tercer sector) y, en caso afirmativo, a cuál,

- un individuo o grupo social no organizado institucionalmente y, en caso afirmativo, a cuál o cuáles.

- Soluciones (VR), mediante la cual se reconoce si se explicita la necesidad de una solución al problema tal como es presentado, distinguiendo entre 1. Sí / 2. No. En caso afirmativo, se registra el minuto en el que la mención aparece y se identifica si la información sugiere que la habilidad para resolver el problema está en manos de:

- alguna institución del Estado,

- una institución no estatal (privada o del tercer sector), o

- un individuo o grupo de individuos no organizados institucionalmente.

- Evaluación moral (VI), en la cual se recoge la presencia o no de aprobación/ desaprobación y castigo/recompensa. Tanto en caso de identificarse aprobación o desaprobación como castigo o recompensa, se indica el minuto en el que se lo hace y se reconocen los posibles portavoces de estas evaluaciones morales:

- presentador,

- fuente de información,

\footnotetext{
El mismo Aristóteles distinguió como extratécnicas a aquellas pruebas que no son compuestas por medio del discurso retórico sino cuya existencia es previa. Tal como las define Barthes (1974), "escapan a la libertad de crear el objeto contingente; se encuentran fuera del orador [...]; son razones inherentes a la naturaleza del objeto [...] Son fragmentos de realidad que pasan directamente a la dispositio, por un simple hacerlos resaltar, no por transformación" (p. 45).

${ }^{10}$ A diferencia de las variables manifiestas, que se refieren a los elementos que están físicamente presentes en los mensajes y que por ello pueden identificarse y cuantificarse con facilidad, las latentes remiten a aspectos no observables directamente. En consecuencia, deben ser inferidos a partir de uno o más indicadores manifiestos (Igartua, 2006; Neuendorf, 2002).
} 
Austral Comunicación

Volumen 7 número 2 (diciembre de 2018): 229-250. ISSN 2313-9129

- movilero / cronista,

- columnista,

- otro no identificado, $\mathrm{u}$

- otro no contemplado en las categorías anteriores.

La quinta dimensión, tratamiento de las fuentes de información, identifica los actores con capacidad de incidir en el encuadre general de los hechos que queda plasmado en la pieza periodística. Para ello, es importante indagar no solo la presencia/visibilidad del/los actor/es involucrado/s, sino además constatar en qué medida el encuadre brindado por la fuente es coherente con el modo en que el medio construye el acontecimiento. Se releva, para el caso de las primeras cinco fuentes citadas, identificando:

- Tipo (VI), que discrimina entre: 1. Personal, cuando se trata de un sujeto individual o colectivo, o cuando se cita a una institución / 2. Documental, cuando se citan documentos públicos o privados. De citarse una fuente personal, puede identificarse a:

- una persona individual, cuando se la presenta por su nombre, apellido, apodo o rol,

- colectivos de identificación ${ }^{11}$, si se lo designa explícitamente en el discurso y es una entidad enumerable, es decir si se la puede cuantificar y fragmentar,

- colectivos de generalización, que no funcionan como operadores de identificación de los actores en presencia en el enunciado y son más amplios que los colectivos de identificación,

- metacolectivos singulares, cuando no admiten ni la cuantificación ni la fragmentación,

- otros no considerados en las categorías anteriores,

- 99. no es posible identificar.

- Modo de empleo del discurso referido (VR), que distingue si el fragmento evocado se ha realizado en: 1. Modo directo, cuando las fuentes se expresan por sí mismas en la noticia, ya sea visual o audiovisualmente / 2. Modo indirecto, cuando el discurso del medio recupera lo dicho por una fuente.

- Nivel de la fuente (VI), que dirime si es: 1 . Fuente de primer orden (cuando la fuente citada produce o habilita el acceso a la información por ser protagonista o testigo directos de los acontecimientos) / 2. Fuente de segundo orden (aquellas que no se relacionan directamente con los hechos, sino que proveen material ya producido a partir de sus fuentes particulares) / 3. Fuente no identificada

${ }^{11}$ Todos los distintos tipos de colectivos han sido tomados de Verón (1987b). 
Natalia Aruguete, Natalia Raimondo Anselmino, Esteban Andrés Zunino, Nadia Sabrina Koziner, Gabriela Fabbro

Matriz para el estudio de noticias televisivas sobre delito, violencia e inseguridad: una articulación teórico-metodológica

$\mathrm{u}$ off the record (en los casos en que no se identifica el individuo o institución que proveyó la información).

- Personalización (VI), que diferencia entre: 1. Fuente personalizada (cuando se menciona como proveedora de la información a una persona o institución individualizada que actúa como informante directo por su cercanía con el acontecimiento relatado) / 2. Fuente no personalizada (cuando se refiere a individuos proveedores de la información que no son identificados explícitamente) / 99. No corresponde (no hay).

- Institucionalidad (VI), que discrimina entre: 1. Fuente oficial (cuando proviene del gobierno, de alguno de sus ministerios, secretarías u otros organismos públicos dependientes, así como del Poder Legislativo o del Judicial) / 2. Fuente no oficial (cualquier persona o institución que no es un funcionario público ni dependencia estatal) / 3. Otros no incluidos en las categorías anteriores / 99. No corresponde (no hay).

- Adhesión del enunciador mediático a sus dichos (VI), que precisa si: 0. Es ambigua o indefinida (cuando la posición del medio respecto de los dichos de la fuente no es explícita) / 1 . Se adhiere a los dichos de la fuente toda vez se les reconozca autoridad en los datos que provea o se apoye explícitamente la postura que manifieste / 2. Se toma distancia de los dichos de la fuente cuando lo expresado por el medio contradiga la percepción de los hechos que declare la fuente.

Finalmente, la sexta dimensión, aspectos narrativos, aplica categorías analíticas propias de la narrativa audiovisual que, como ya se señaló, indaga en el proceso y en los mecanismos narrativos "de la imagen visual y acústica [...], tanto en su forma como en su funcionamiento" (García Jiménez, 1993, p.13-14). Esta dimensión supone las siguientes variables:

- Focalización que adopta el relato (VI), según la clásica definición propuesta por Genette (1989) recuperada en Cuevas (2014) para explicar la perspectiva narrativa. De este modo, esta variable observa la presencia de: 1 . Relato omnisciente: el narrador todo lo sabe / 2. Interna: coincide con el punto de vista de un sujeto de la acción. Es decir, adopta la perspectiva del protagonista / 3. Externa: el narrador dice menos de lo que sabe un personaje, se sale de la perspectiva del protagonista / 4. Espectatorial: es aquella situación en la que se concede ventaja cognitiva al espectador respecto de los sujetos de la acción.

- Ocularización (VR), que atiende a la perspectiva visual (Gaudreault \& Jost, 1995) o relación entre lo que la cámara muestra y lo que los sujetos protago- 
Austral Comunicación

Volumen 7 número 2 (diciembre de 2018): 229-250. ISSN 2313-9129

nistas supuestamente ven. Permite computar si aparece al menos una vez cada uno de los siguientes tipos ( $y$, en caso afirmativo, se describe una escena representativa y el minuto en el que aparece): 1 . Ocularización 0 (cuando no adopta la perspectiva visual de los sujetos de la acción) / 2. Interna (cuando adopta la perspectiva visual de alguno de los sujetos de la acción, es decir que lo que se muestra se corresponde con lo que ve alguno de los sujetos involucrados en el relato).

- Auricularización (VR) o banda sonora (Gaudreault \& Jost, 1995), que describe tanto los diálogos como la música, los silencios o los efectos sonoros. Se computa si aparece al menos una vez cada uno de los siguientes tipos ( $y$, en caso afirmativo, se describe una escena representativa y el minuto en el que aparece): 1. Nivel 0 (cuando no adopta la perspectiva auricular -filtro- de los sujetos de la acción / 2. Interna (cuando adopta la perspectiva auricular -filtro- de uno/s de los sujetos de la acción, es decir, lo que se escucha se corresponde con lo que dice alguno de ellos).

- Recursos visuales (VR), que releva aquellos componentes de la banda de imagen, de los cuales se describen: 1. Videograph, también llamado zócalo (texto sobreimpreso que aparece por debajo de una imagen; puede llevar el título de la noticia, tomar palabras textuales del sujeto entrevistado, brindar información y datos o calificar lo mostrado; puede quedar fijo o circular de corrido) / 2. Efecto especial (en tanto efecto visual producido por la edición) / 3. Pantalla fragmentada (que se utiliza para presentar más de una imagen en el mismo encuadre; por ejemplo, pantalla partida).

- Recursos sonoros (VR), que son los componentes de la banda de sonido, de los cuales se describen: 1. Texto oral (parlamento, testimonio o comentario emitido oralmente) / 2. Música (melodía musical) / 3. Efectos de edición (efectos de la banda sonora realizados en la etapa de edición) / 4. Sonido ambiente (toma de sonido en directo) / 5. Silencio (ausencia significativa de banda sonora).

- Tipo de montaje (VI), que describe la función principal de este "principio que regula la organización de los elementos visuales y sonoros, o el conjunto de tales elementos, yuxtaponiéndolos, encadenándolos, y/o regulando su duración" (Aumont \& Bergala, 1985, p. 62). Su primera función es la narrativa, que permite que el texto audiovisual sea comprensible y tenga sucesión lógica de los acontecimientos narrados; a la cual se suma la función expresiva, "que implica que el montaje por sí mismo expone una idea, mensaje o provoca una emoción" (Delgadillo Velasco, 2011: s/p). El montaje así se configura como un proceso productor de sentido (Delgadillo Velasco, 2011). En este caso, se identifican: 
Natalia Aruguete, Natalia Raimondo Anselmino, Esteban Andrés Zunino, Nadia Sabrina Koziner, Gabriela Fabbro

Matriz para el estudio de noticias televisivas sobre delito, violencia e inseguridad: una articulación teórico-metodológica

1. Montaje descriptivo (cuya función es estrictamente narrativa y permite que el texto sea comprensible y lógico, sin manipulaciones) / 2. Montaje probatorio, propio de la narrativa de no ficción que presenta una construcción espacio-temporal particular en donde la construcción de continuidad en los relatos (Nichols, 1997), especialmente en los informes, está al servicio de la argumentación que los sostiene.

\section{Consideraciones finales}

Como se ha señalado, las distintas dimensiones de la matriz que han sido desglosadas en este artículo -así como las más de setenta variables que estas comprenden- son resultado de una triangulación teórico-metodológica que derivó en una herramienta no solo provechosa para el análisis del contenido sino, también, fértil para el reconocimiento futuro de algunas manifestaciones de la puesta en discurso.

En este trabajo nos referimos a estrategias de investigación trianguladas que se orientan hacia unidades comunes de observación por cuanto buscamos que haya cierto grado de acuerdo -nunca un consenso pleno- sobre tales objetos.

Como resultado de la articulación de las perspectivas así integradas, por ejemplo, no solo se han agregado categorías nuevas que completan los elementos de encuadre (frame elements) identificados por los trabajos clásicos inscriptos en esta perspectiva, sino que, también, se han recreado y redefinido algunas de las variables propias del framing o del standing que, en otros contextos analíticos, son analizadas desde una aproximación completamente deductiva.

La presentación de una matriz de análisis para el estudio de noticias sobre delito, violencia e inseguridad tiene por finalidad constituirse en un aporte para el estudio de los contenidos y discursos mediáticos. Alejados de la pretensión de objetividad científica inmanente al desarrollo de un protocolo metodológico, la potencia de la herramienta que aquí se expuso radica, justamente, en que es el resultado de la puesta en cuestión -y discusión- de enfoques frecuentemente utilizados en el análisis de coberturas informativas, aunque de manera aislada y hasta contrapuesta. Un profundo esfuerzo de reflexión teórica y epistemológica, siempre en diálogo con el objeto de estudio, sedimentó en la elaboración de un instrumento novedoso. La herramienta, susceptible de ser aplicada sistemáticamente a todas las unidades de análisis de un conjunto de noticias extenso, posibilitó construir un volumen importante de datos cuantitativos y de manifestaciones concretas de la puesta en discurso que, combinadamente, aportan a la comprensión, interpretación y discusión científica sobre asuntos centrales de las agendas mediática, política y pública contemporáneas. 
Austral Comunicación

Volumen 7 número 2 (diciembre de 2018): 229-250. ISSN 2313-9129

\section{Referencias}

Adelstein, A. (1996). Enunciación y crónica periodística. Buenos Aires: Ars.

Amadeo, B. (2008). Framing: Modelo para armar. En M. T. Baquerín de Riccitelli (Ed.), Los medios ¿aliados o enemigos del público? (pp. 183-281). Buenos Aires: EDUCA

Aumont, J., Bergala, A., Marie, M., \& Marc, V. (1985). Estética del cine: espacio fílmico, montaje, narración, lenguaje. Barcelona: Paidós.

Bailone, M. (2016). Genocidio, jurisdicción universal y criminología cautelar. Derecho Penal y Criminología, 5(6), 63-69.

Barroso, J. (2002). Realización de los géneros televisivos. Madrid: Síntesis.

Barthes, R. (1974). Investigaciones retóricas I. La antigua retórica. Ayudamemoria. Buenos Aires: Tiempo Contemporáneo.

Calzado, M. (2012). Ciudad segura. Vecindad, víctimas y gubernamentalidad. Notas sobre la campaña electoral del PRO en la Ciudad de Buenos Aires (2011). Trabajo presentado en las VII Jornadas de Sociología de la Universidad Nacional de La Plata "Argentina en el escenario latinoamericano actual: debates desde las ciencias sociales" de la Universidad Nacional de La Plata, Argentina.

Calzado, M. (2015). Inseguros. El rol de los medios y la respuesta política frente a la violencia de Blumberg a hoy. Buenos Aires: Aguilar.

Casetti, F., \& Di Chio, F. (1999). Análisis de la televisión: instrumentos, métodos y prácticas de investigación. Barcelona: Paidós.

Cebrián, M. (1992). Géneros informativos audiovisuales: radio, televisión, periodismo gráfico, cine, vídeo. Madrid: Ciencias.

Charron, J. (1998). Los medios y las fuentes. Los límites del modelo de agenda setting. En M. J. Gilles Gauthier, A. Gosselin, \& J. Mouchon (Eds.), Comunicación y politica (pp. 72-93). Barcelona: Gedisa.

Cohen, A. \& Wolsfeld, G. (Eds.) (1993). Framing the intifada: people and media. New Jersey: Ablex.

Colle, R. (2011). El análisis de contenido de las comunicaciones. Colección Cuadernos Artesanos de Latina, 11-12-13.

Cuevas, E. (2014). La narratología audiovisual como método de análisis. Institut de la Comunicació (UAB) Obtenido de http://hdl.handle.net/10171/35350.

Delgadillo Velasco, R. (2011). Teorías sobre montaje audiovisual. Punto Cero, 16(22), 69-77.

Denzin, N. K. (1978). The research act: A theoretical introduction to sociological methods $2^{\text {nd }}$ edition. New York: McGraw-Hill Book Company.

Entel, A. (2007). La ciudad y los miedos: La pasión restauradora. Buenos Aires: La Crujía.

Entman, R. M. (1993). Framing: Toward Clarification of a Fractured Paradigm. Journal of Communication, 43(4), 51-58. https://doi.org/10.1111/j.1460-2466.1993.tb01304.x. 
Natalia Aruguete, Natalia Raimondo Anselmino, Esteban Andrés Zunino, Nadia Sabrina Koziner, Gabriela Fabbro

Matriz para el estudio de noticias televisivas sobre delito, violencia e inseguridad: una articulación teórico-metodológica

Entman, R. M. (2003). Cascading Activation: Contesting the White House's Frame After 9/11. Political Communication, 20(4), 415-432. https://doi. org/10.1080/10584600390244176.

Farré, M. (2004). El noticiero como mundo posible: Estrategias ficcionales en la información audiovisual. Buenos Aires: La Crujía.

Fernández Pedemonte, D. (2010). Conmoción pública: Los casos mediáticos y sus públicos. Buenos Aires: La Crujía.

Ferree, M. M., Gamson, W. A., Gerhards, J., \& Rucht, D. (2002). Shaping Abortion Discourse. Democracy and the Public Sphere in Germany and the United States. Cambridge.

Gallart, M. A. (2002) Veinte años de educación y trabajo: La investigación de la formación $y$ la formación de una investigadora. Montevideo: OIT/Cinterfor.

Gans, H. J. (2004). Deciding What's News: A Study of CBS Evening News, NBC Nightly News, Newsweek, and Time. $2^{\text {nd }}$ edition. Evanston, Illinois: Northwestern University Press.

García, J. B. (2002). Realización de los géneros televisivos. Madrid: Síntesis.

García Jiménez, J. (1993). Narrativa audiovisual. Madrid: Cátedra.

Gaudreault, A. \& Jost, F. (1995). El relato cinematográfico: Cine y narratología. Madrid: Paidós.

Genette, G., \& Crampé, B. (1988). Structure and Functions of the Title in Literature. Critical inquiry, 14(4), 692-720.

Genette, G. (1989) Figuras III. Barcelona: Lumen.

Hills, G. (1987). Los informativos en radiotelevisión. Madrid: Instituto Oficial de Radio y Televisión, Ente Público RTVE.

Igartua, J. J. (2006). Métodos cuantitativos de investigación en comunicación. Barcelona: Bosch.

INDEC (2010). Censo Nacional de Población, Hogares y Viviendas 2010. Censo del Bicentenario. Ciudad Autónoma de Buenos Aires: Instituto Nacional de Estadísticas y Censos.

Kessler, G. (2009). El sentimiento de inseguridad. Sociología del temor al delito. Buenos Aires: Siglo XXI.

Kessler, G. (2013). Ilegalismos en tres tiempos. En Castel, R., Kessler, G. Merklen, D. \& Murard, N. (Eds.) Individuación, precariedad, inseguridad (pp. 109-165). Buenos Aires: Paidós.

Killias, M. (1991). Précis de criminologie. Bern: Stämpfli.

Lagos, M., \& Dammert, L. (2012). Latinobarómetro: la seguridad ciudadana-el problema principal de América Latina. Lima. Obtenido de http://www.latinobarometro.org/ documentos/LATBD_La_seguridad_ciudadana.pdf. 
Austral Comunicación

Volumen 7 número 2 (diciembre de 2018): 229-250. ISSN 2313-9129

Lorenç Valcarce, F. (2009). Orden, derechos y delitos. La inseguridad en la agenda pública argentina. Revista de Ciencia Política El Príncipe, 3(2), 1-26.

Martini, S. (2012). Opinión pública, medios masivos y control social. ¿Los bárbaros están entre nosotros? En Martini, S. \& Contursi, M. E. (Eds.) Comunicación pública del crimen y gestión del control social (pp. 19-46). Buenos Aires: La Crujía.

Matthes, J., \& Kohring, M. (2008). The content analysis of media frames: Toward improving reliability and validity. Journal of Communication, 58(2), 258-279.

Muratori, M., \& Espíndola, S. (2016). Documento de Trabajo. Observatorio de la Deuda Social Argentina. Buenos Aires: Universidad Católica Argentina. Obtenido de http:// www.uca.edu.ar/uca/common/grupo68/files/2016-Observatorio-DocumentoVictimizacion-Inseguridad-Subjetiva.pdf.

Neuendorf, K. (2002). The content analysis guidebook. Thousand Oaks; CA: Sage.

Nichols, B. (1997). La representación de la realidad: cuestiones y conceptos sobre el documental. Madrid: Paidós.

Orza, G. F. (2002). Programación televisiva: un modelo de análisis instrumental. Buenos Aires: La Crujía.

Raimondo Anselmino, N. (2011). O ocaso do modelo intencional: como pensar a noção de 'estratégia discursiva' sob o olhar sócio-semiótico. Revista Semeiosis, 2.

Redorta, J. (2004). Cómo analizar los conflictos: la tipología de los conflictos como herramienta de mediación. Barcelona: Paidós.

Rodríguez Alzueta, E. (2014). Temor y control: la gestión de la inseguridad como forma de gobierno. Buenos Aires: Futuro Anterior.

Sánchez, J. F. (1990). Títulos y titulares. Sobre las funciones de la titulación periodística. Pamplona: EUNSA.

Sigal, S. \& Verón, E. (2008) Perón o muerte. Los fundamentos discursivos del fenómeno peronista. Buenos Aires: Eudeba.

Sozzo, M. (2016). Postneoliberalismo y penalidad en Argentina (2003-2014). En Sozzo, M. (Ed.), Postneoliberalismo y penalidad en América del Sur (pp. 189-283). Buenos Aires: CLACSO.

Verón, E. (1987a). Prefacio a la segunda edición Construir el acontecimiento. Los medios de comunicación masiva y el accidente en la central nuclear de Three Mile Island (pp. I-VII). Buenos Aires: Gedisa.

Verón, E. (1987b). La palabra adversativa. En Verón, E.; Arfuch, L.; Chirico, M. M.; De Ipola, E.; Goldman, N.; Bombal, M. I. y Landi, O., El discurso político. Lenguajes y acontecimientos (pp. 11-26). Buenos Aires: Hachette.

Verón, E. (1998) La semiosis social. Fragmentos de una teoría de la discursividad. Buenos Aires: Gedisa.

Verón, E. (2004). Fragmentos de un tejido. Buenos Aires: Gedisa. 
Natalia Aruquete, Natalia Raimondo Anselmino, Esteban Andrés Zunino, Nadia Sabrina Koziner, Gabriela Fabbro

Matriz para el estudio de noticias televisivas sobre delito, violencia e inseguridad: una articulación teórico-metodológica

Zaffaroni, E. R. (2012). Crímenes de masa. Buenos Aires: Ediciones Madres de Plaza de Mayo.

Zaffaroni, E. R. (2016). Derecho penal humano y poder en el siglo XXI. Conferencia dictada en la Ordem dos Advogados do Brasil, Seccional Distrito Federal, Brasilia, el 6 de junio de 2016. 